\title{
Current Trend of Caesarean Section in a Tertiary Care Military Hospital
}

\author{
Ara $\mathrm{I}^{1 *}$, Solaiman $\mathrm{SM}^{2}$, Hasan $\mathrm{MMS}^{2}$, Sultana $\mathrm{R}^{1}$ \\ ${ }^{1}$ Combined Military Hospital, Savar, Dhaka, Bangladesh \\ ${ }^{2}$ Army Headquarters, Dhaka Cantonment, Dhaka, Bangladesh
}

\begin{abstract}
Caesarean section rates are increasing worldwide. It contributes to substantial maternal and perinatal morbidity and mortality. South Asian countries including Bangladesh have recorded substantial increases in caesarean section rates over the past decade. In Bangladesh, the caesarean incidence rate was 2.6 percent in 2001 and 12.2 percent in 2010. So, the incidence rate increased five times over the last decade. This descriptive cross sectional study was conducted at Combined Military Hospital (CMH), Savar, Dhaka during January 2014 to December 2015, aimed to assess the current trend of mode of deliveries of babies. A total of 1253 pregnant women who attended this tertiary level hospital, for their delivery, were enrolled in the study. The study subjects were selected by simple random sampling. A pretested structured questionnaire was used for data collection. The mean age of respondents was $25.81 \pm 4.46$ years. Most (72\%) of them were between 20-29 years of age. Some thirty nine percent of the respondents completed secondary level of education. The study showed that among 1253 respondents, $70.3 \%$ underwent CS and $29.7 \%$ had normal vaginal delivery. Most common indication for caesarean section was previous CS (42.4\%) that contributed an increase in total caesarean birth. Lowest incidence was antepartum haemorrhage $(0.9 \%)$. Prolonged labour and cervical dystocia, hypertensive disorder, malpresentation were also contributing factors for caesarean section. So, previous caesarean birth was the most important factor in making decision about the way of delivery. Based on the study findings, to decrease the rate of caesarean section, careful monitoring of the foetus at all levels of health care facilities for critical decisions are suggested.
\end{abstract}

Keywords: Caesarean section, Indications, Trend, Prolonged labour

\section{Introduction}

Caesarean delivery, also known as caesarean section (CS), is a form of childbirth in which a surgical incision is made through a mother's abdomen and uterus to deliver the baby. ${ }^{1}$ It is one of the most common surgical procedures among women. The introduction of caesarean section surgery was associated with an improvement in maternal and perinatal health outcomes. ${ }^{2}$ Access to comprehensive emergency obstetric care, including $\mathrm{CS}$, is key to preventing the estimated 287000 maternal and 2.9 million neonatal deaths worldwide every year. ${ }^{3,4}$ Although debate continues about how to quantify the need for lifesaving CS, a World Health Organization (WHO) report suggested that the optimal population range for CS rate is between $5 \%$ and $15 \%$, This endures as a reference. ${ }^{5,6}$ However, WHO has stated that no empirical evidence exists for an ideal caesarean rate, but "what matters most is that all women who need CS actually receive them". ${ }^{7}$

Caesarean section rates are increasing worldwide, albeit unequally: a recent analysis of Demographic and Health Survey (DHS) data in 26 South Asian and sub-Saharan African countries found that rates were highest among the 'urban rich' in all countries, and lowest among the 'rural poor' in 18 countries. $^{8}$ In all countries, fewer than $5 \%$ of mothers in the poorest wealth quintile delivered by caesarean. ${ }^{9}$ In areas with very high mortality rates, such as Africa, inadequate availability of CS contributes to substantial maternal and perinatal morbidity and mortality. ${ }^{10}$ Conversely, in many developed countries, concerns exist about high rates of $\mathrm{CS}$, since increasing rates of this procedure show little evidence of further improvement in perinatal outcomes. ${ }^{11}$ South Asian countries have recorded substantial increases in $\mathrm{CS}$ rates over the past decade. In Bangladesh, rates 
rose from $2 \%$ (2000) to $17 \%$ (2011); in India, from $3 \%$ (1992) to $11 \%$ (2006); and in Nepal, from $1 \%$ (2000) to $5 \%$ (2011). ${ }^{12-14}$

Caesarean section carries its own risks for maternal and infant morbidity and for subsequent pregnancies. ${ }^{15}$ The procedure is associated with significant increases in maternal and infant morbidity and mortality, particularly in lowincome countries. Increases in maternal morbidity are particularly prevalent after an emergency CS or a CS performed during the second stage of labor. ${ }^{16}$ AWHO survey of 373 facilities across 24 countries found that unnecessary caesareans were associated with an increased risk of maternal mortality and serious outcomes for mothers and newborn infants, compared with spontaneous vaginal delivery. ${ }^{17}$ Many factors have contributed to the increasing rates of CS including medical and non-medical factors. Medical factors include increases in maternal age and body mass index and changes in obstetric practices and technologies. Non-medical factors include CS requested by the mother, the inappropriate organization of maternity care and physician- induced demand for CS. ${ }^{18,19}$ There is significant variation in the CS rate in terms of socioeconomic status. ${ }^{20} \mathrm{~A}$ systematic review and meta-analysis of observation studies revealed that the preference for a CS in women is greater than $15 \%$. Recent evidence also shows that the demand for a CS among young, educated women residing in urban areas has increased. ${ }^{21}$ According to the limited available research, the CS in Bangladesh is considerably higher than the recommended upper limit of $10 \% .^{22}$

The proportion of women giving birth by CS in private rather than public facilities also varied widely between settings. In Bangladesh, only $21 \%$ of women delivered in a health facility, around half of them in the private/charitable sector, but $73 \%$ of private facility births were by caesarean section. In 2011, three in five facility births were delivered by CS which reflects the historicaltrend that in 2001-2003, nearly half of deliveries in private facilities in Bangladesh were performed by $\mathrm{CS}^{23}$ Data from rural area, socioeconomically disadvantaged communities in three districts of Bangladesh, Bogra, Maulvibazaar and Faridpur, suggestthat high CSrates in private facilities arenot merely an issue for wealthy urban mothers.
Although some study from Bangladesh suggests that mothers may have a preference for caesarean delivery because of fear of labour pain or a desire to select an auspicious date for the birth, other studies also highlight women's fears of CS and their distrust of health providers who claim high costs for the procedure. The lack of association between caesareans and complications in pregnancy or delivery, high financial incentives given to providers for performing CS and the requirement for junior doctors to 'practise' their surgical skills, suggest that CS is being used over and above clinical need. A possible explanation for the significant interactive associations between maternal education and caesarean delivery in public and private facilities in Bangladesh is that well-educated women maybe delivering in more expensive or highly rated institutions, which may in turn be more likely to perform CS for financial reasons and if they act as training centers for junior doctors. $^{24}$

Recent ecological analyses also highlighted strong associations between caesarean delivery and increased neonatal mortality in countries with low and medium caesarean section rates. ${ }^{25}$ Unnecessary caesareans lead to considerable costs for families and health systems: an estimated 6.2 million unnecessary procedures were performed in 2008, costing approximately US $\$ 2.32$ billion. ${ }^{26}$ The literature from other settings indicates that increases in caesarean sections are shaped by supply and demand pressures: providers often have financial incentives to intervene surgically, and women of higher socioeconomic status are also more likely to opt for caesareans. ${ }^{27,28}$ Some women consider $\mathrm{C}$ - section is more advantageous than natural birth. They think that a C-section is a modern procedure to have a baby, involving the use of technology. ${ }^{29}$

Considering the information, the present study was conducted in a combined military hospital at Savar, Bangladesh situated adjacent to the capital city Dhaka to assess the current trend of the caesarean section and its indication, over the two successive years.

\section{Materials and methods}

This descriptive cross sectional study was conducted in the department of Obstetrics and 
Gynecology, Combined Military Hospital, Savar, Bangladesh during the period of January 2014 to December 2015.

The study population was pregnant wives of soldiers in defense community. who were admitted in the department of Obstetrics and Gynecology, Combined Military Hospital, Savar to deliver their babies were enrolled in the study. A total of 1253 pregnant women were selected by simple random sampling technique. Permission of the hospital authority was obtained. An informed consent was taken from each participant to maintain full autonomy of the participants.

Study participants from the Savar or its surrounding area, of any age, religion or custom were included in the study. Technically booked mothers were defined as those who had at least three antenatal visits at study center while unbooked mothers included those who had no or less than three antenatal care visits during their whole pregnancy at study center and those who were referred at study center to manage emergency from medical centers and hospitals other than the study centre. Pregnant mothers other than wives of soldiers of defense community were excluded from the study.

The data were collected by face to face interview. All mothers who delivered during the study period and freely consented to participate were interviewed personally either on the day or day after delivery regarding their antepartum, intrapartum and postpartum delivery experiences.

Collected information was recorded in a pretested structured questionnaire. The questionnaire consisted of demographic variables,obstetric history, maternaland neonatal outcome were designed to meet the requirements of the study. Demographic variables included age, socioeconomic status and booking status. Obstetric history included parity status, maternal health before and during pregnancy, significant clinical events in previous pregnancy and detailed information regarding complications occurred during intrapartum and postpartum period.Maternal outcome including mode of delivery, occurrence of anaemia, postpartum haemorrhage and maternal death were recorded. Neonatal outcome such as gestational age,birth- weight, perinatal mortality etc. were also documented. Investigations including complete blood count, urine analysis, random blood sugar, blood grouping, HIV antibody analysis, hepatitis C and hepatitis B antigens, bleeding time, clotting time and baseline ultrasonography were also recorded.

The statistical analyses were done by Statistical Package for Social Sciences (SPSS) version 16.0 for windows. The result was expressed in mean $\pm S D$ in case of quantitative data and in frequency and percentage in case of qualitative data. Comparison between two successive years was done by Chi-square test. $p$ value $<0.05$ was considered as significant.

\section{Results}

The mean age of respondents was $25.81 \pm 4.46$ years. Almost three-quarters of them (72\%) were in age group 20-29 years. More than one-third $(38.7 \%)$ of the respondents completed secondary level of education. (figure-1)

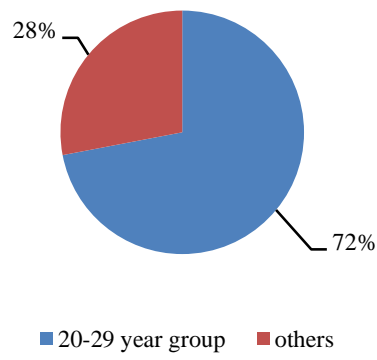

Figure 1: Age distribution of the participants

Of the total 1253 respondents, 881(70.31\%) patients underwent CS and 372 (29.69\%) had normal vaginal delivery (NVD). Delivery by caesarean section was relatively more in the year 2014 than in the year 2015 (71.18\% vs $69.42 \%)$, however the difference was not statistically significant (table I).

Table-I: Mode of delivery

\begin{tabular}{llllll}
\hline $\begin{array}{l}\text { Mode of } \\
\text { delivery }\end{array}$ & $\begin{array}{l}\text { Years } \\
2014\end{array}$ & $\begin{array}{l}2015 \\
\mathrm{f}(\%)\end{array}$ & $\begin{array}{l}\text { Total } \\
\mathrm{f}(\%)\end{array}$ & & \\
& $\mathrm{f}(\%)$ & $429(69.4$ & $881(70$. & 0.466 & 0.494 \\
\hline Caesarean & $452(71.2$ & $4 \%)$ & & NS \\
section & $\%)$ & $\%)$ & $3 \%)$ & \\
Normal & $183(28.8$ & $189(30.6$ & $372(29$. & & \\
vaginal & $\%)$ & $\%)$ & $7 \%)$ & & \\
delivery & & & & & \\
Total & $635(10$ & $618(100$. & $1253(1$ & & \\
& $0 \%)$ & $0 \%)$ & $00.0 \%)$ & & \\
\hline
\end{tabular}

$\mathrm{NS}=$ not significant 
Table II: Type of caesarean sections

\begin{tabular}{|c|c|c|c|c|c|}
\hline \multirow{2}{*}{$\begin{array}{c}\text { Type of } \\
\text { caesarean } \\
\text { section }\end{array}$} & \multicolumn{3}{|c|}{ Years } & \multirow[t]{2}{*}{$\chi^{2}$} & \multirow[t]{2}{*}{$p$} \\
\hline & $\begin{array}{c}2014 \\
\text { number } \\
(\%)\end{array}$ & $\begin{array}{c}2015 \\
\text { Number(\%) }\end{array}$ & $\begin{array}{c}\text { Total } \\
\text { Number } \\
(\%)\end{array}$ & & \\
\hline Emergenc & 127 & $61(14.2 \%)$ & 188 & 25.25 & $<.00$ \\
\hline $\mathrm{y}$ & $\begin{array}{c}(28.1 \% \\
)\end{array}$ & & $(21.3 \%)$ & 5 & 1 \\
\hline Elective & $\begin{array}{c}325 \\
(71.9 \%\end{array}$ & $\begin{array}{l}368(85.8 \% \\
)\end{array}$ & $\begin{array}{l}693(78.7 \% \\
)\end{array}$ & & \\
\hline Total & $\begin{array}{c}) \\
452 \\
(100 \%)\end{array}$ & $\begin{array}{l}429 \\
(100 \%) \\
\end{array}$ & $881(100)$ & & \\
\hline
\end{tabular}

Of the total $881 \mathrm{CS}, 188$ (21.34\%) patients, had emergency indications and 693(78.66\%) patients had elective CS. Emergency indications of CS was significant high in year 2014 than in the year 2015 $(28.10 \%$ vs $14.22 \%, p<0.001)($ table II)

Table-III: Medical and maternal indication of caesarean section $(\mathrm{n}=881)$

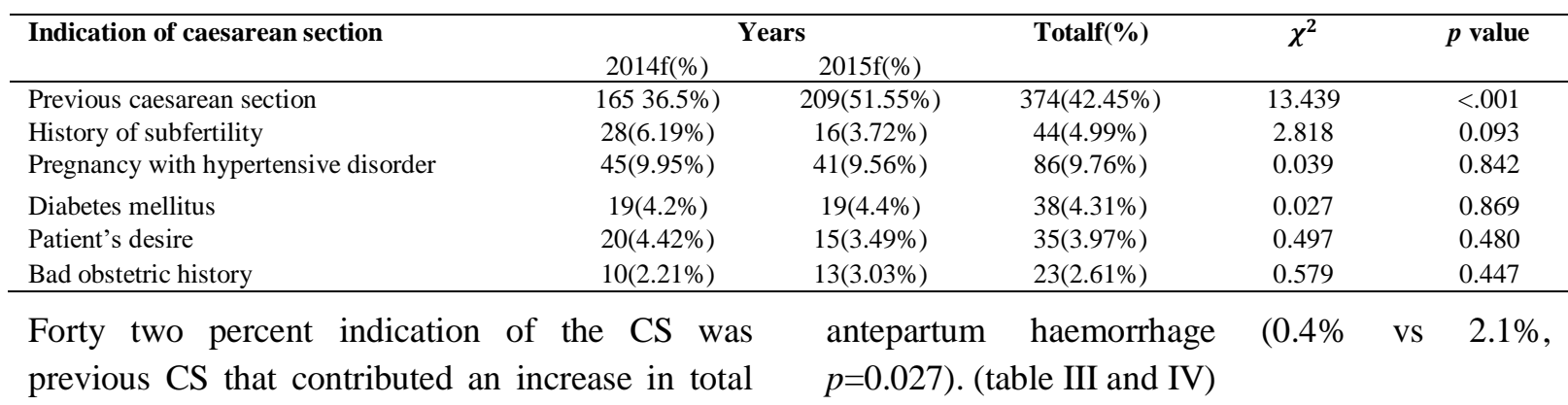
caesarean birth. This indication was significantly higher in 2015 than in 2014 (36.5\% in year 2014 and $51.6 \%$ in year $2015, p<0.001)$. Other less common indication with significant difference between two study years were postdated pregnancy with oligohydramnios $(9.5 \%$ vs $1.4 \%$, $p<0.001$ ), premature rupture of membrane and oligohydramnios ( $4.4 \%$ vs $1.96 \%, p=0.03)$ and

The indications with no significant difference between two study years were prolonged labour and cervical dystocia, history of subfertility, mal presentation, diabetes mellitus, foetal distress, patient's desire, placenta praevia, bad obstetric history and multiple pregnancies. (table III and IV)

Table-IV: Obstetric and fetal indication of caesarean section $(\mathrm{n}=881)$

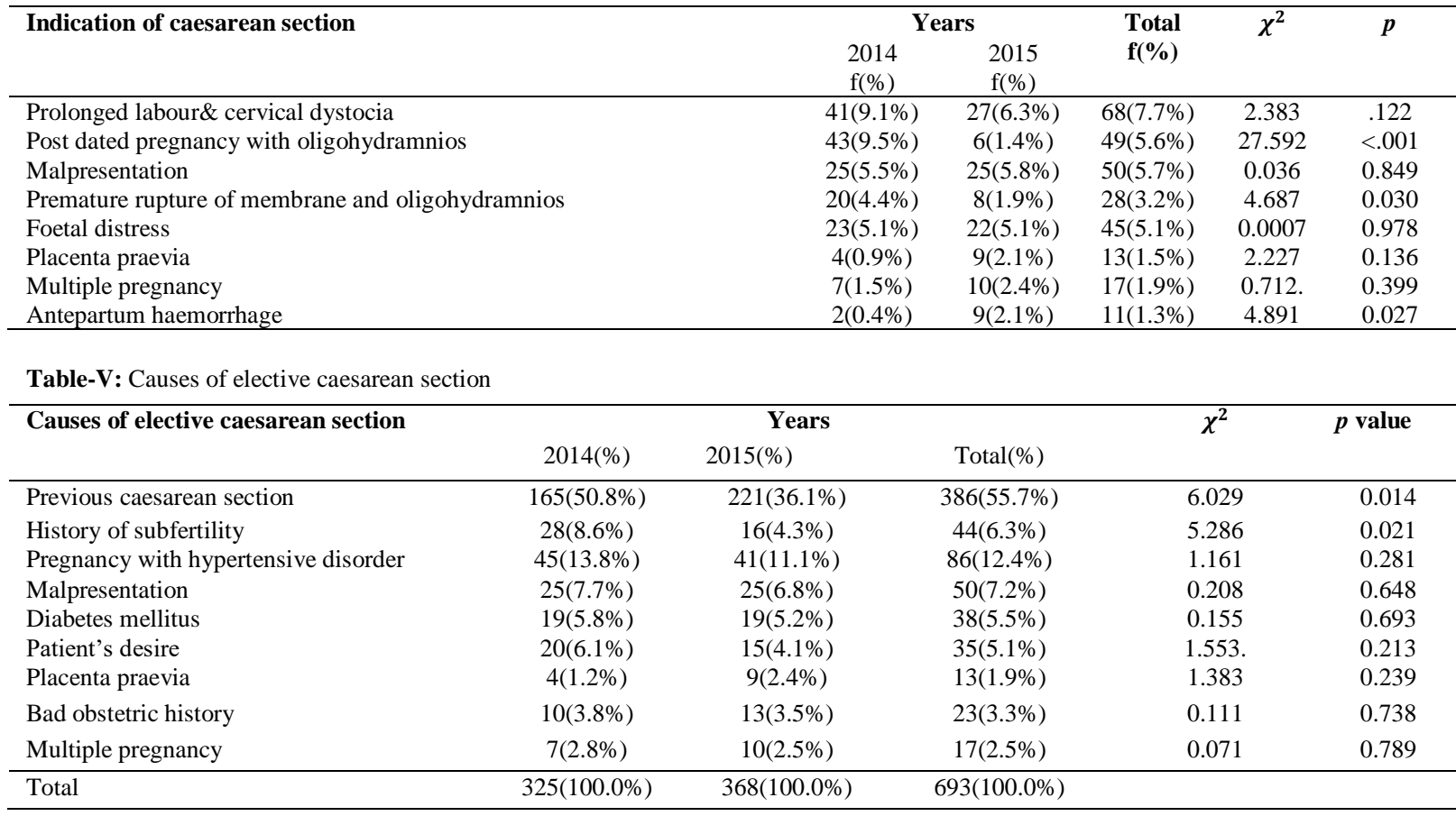

Most common causes for elective CS included previous CS in 386(55.70\%) patients followed by pregnancy with hypertensive disorder in $86(12.41 \%)$ patients, malpresentation in 50 
(7.22\%), history of subfertility in $44(6.35 \%)$, diabetes mellitus in $38(5.48 \%)$ patient's desire in $35(5.05 \%)$, bad obstetric history in $23(3.32 \%)$, and multiple pregnancy in $17(1.93 \%)$, placenta praevia in $13(1.88 \%)$, patients (table V)

Previous CS (55.7\%)\%)was significantly higher in 2014 than in 2015 (50.8\% vs $36.1 \%, p=0.014$ ) followed by history of subfertility which was also significantly higher in 2014 than 2015 (8.6\% vs $4.35 \%, \mathrm{p}=0.021)$. Other less common causes of elective caesarean section with no significant difference between two study years were pregnancy with hypertensive disorder, malpresentation, diabetes mellitus, patient's desire, placenta praevia, bad obstetric history, and multiple pregnancy (table $\mathrm{V}$ )

\section{Discussion}

The mean age of respondents was $25.81 \pm 4.46$ years. Almost three-quarters of them (72\%) were in age group 20-29 years. Aminu et al found that the mean age of women was $23.5 \pm 4.2$ years which is similar to this study. ${ }^{30}$

CS is used in cases where vaginal delivery is either not feasible or would impose undue risk on mother or baby. Rising incidence can be explained by the fact that our hospital is a tertiary care centre and receives a good number of high risk emergency cases with inadequate or no antenatal care. Most of the patients brought late in labour after being handled by untrained birth attendants and are actually and potentially infected, often anaemic and dehydrated.

In this study, it was to be found that among 1253 deliveries in two successive years (2014 and 2015) 70.3\% patients had CS and29.7\% had NVD. Delivery by CS was relatively more in the year 2014 than in the year 2015 (71.2\% vs 69.4\%), however the difference was not statistically significant (table II). These findings are supported by the findings of other studies. ${ }^{31-33}$

Kaur et al found in their study that the prevalence of caesarean sections was $65 \%$ which was higher over vaginal births $(35 \%) .{ }^{31}$ Shiba et al showed that the cesarean delivery rate increased from $17.17 \%$ to $28.93 \%$, with an increase in primary cesarean delivery rate from $69.03 \%$ in 2001 to
$72.62 \%$ in $2011 .{ }^{32}$ Radha et al also found an increasing of caesarean section among physicians mother of India. ${ }^{33}$ They studied 100 physician mothers and revealed that $60 \%$ underwent caesarean section and $40 \%$ have normal vaginal deliveries between 2000 to 2015, 33\% had caesarean section and $67 \%$ normal vaginal deliveries according to collected data before 2000.Radha et al explained that the rapid socioeconomic changes and the outlook towards medical intervention by the women, families and society are increasingly responsible for the current high incidence of caesarean section in many states and urban centers. ${ }^{33}$

Findings of this study are not consistent with findings of Aminu et al. ${ }^{30}$ They found that the rate of caesarean sections was $21.2 \%$ which was conducted in the five public hospitals of Thakurgaon district of Bangladesh among 2503 deliveries during July to December 2011. Thakurgaon is a peripheral district situated northern part of Bangladesh. Study participants consisted of semi-urban and rural dwellers, with the majority of the population coming from farmers' family. Women and children in the district benefitted from free healthcare under the Maternal and Newborn Health Initiative (MNHI) programme. The public hospitals are situated in the Upazilla level. Patients get themselves admitted in these hospitals directly without being referred by any other physician. Most of the patients treated here are usually without complications. So, the rate caesarean sections are low in these setting.

In the present study, it was to be found that among the total $881 \mathrm{CS}, 21.34 \%$ patients had indications for emergency CS and $78.66 \%$ patients had indications for elective CS. Emergency indications of CS was significant high in year 2014 than in the year 2015 (28.10\% vs $14.22 \%, p<0.001$ (tableIII). These findings are not in agreement with the findings of others. ${ }^{30,32} \mathrm{Aminu}$ et al observed that $68 \%$ of CS was performed as emergency. ${ }^{25}$ Kaur, Singh and Kaur found higher number of emergency (52.3\%) over elective (47.7\%) caesarean sections. ${ }^{31}$

It was to be found that the most common indication for CS was previous CS (42.5\%) 
followed by pregnancy with hypertensive disorder $(9.8 \%)$, prolonged labourand cervical dystocia $(7.7 \%)$ and malpresentation (5.7\%). Other indications included post-dated pregnancy with oligohydramnios (5.6\%),foetal distress $(5.1 \%)$, history of subfertility (5.0\%), diabetes mellitus $(4.3 \%)$, patient's desire $(3.9 \%)$, premature rupture of membrane and oligohydramnios (3.2\%), bad obstetric history (2.6\%), and multiple pregnancy $(1.9 \%)$, placenta praevia $(1.5 \%)$ and antepartum haemorrhage (1.3\%).

Findings of this study are consistent with the findings other studies ${ }^{31-35}$. Aminu et al found that the commonest indications for CS were: previous CS (29.4\%), fetal distress (15.7\%), cephalo-pelvic disproportion $(10.2 \%)$, prolonged obstructed labor $(8.3 \%)$ and post-term dates $(7.0 \%) .{ }^{30}$ Kaur, Singh and Kaurfound that fetal distress, repeat caesarean sections, multiparity, high socioeconomic status, 21 to $30 \mathrm{yrs}$ of age group were the indications of cesarean sections while primiparityand low socioeconomic status were the indications of vaginal births. ${ }^{31}$ Shiba et al found that fetal distress, arrest of descent, multiple gestations, and fetalindications contributed to the increase in the rate of CS. ${ }^{32}$

Rahman et al stated that nine risk factors were found significantly associated with type of delivery. Eight of the risk factors i.e. previous Csection, pregnancy inducedswollen of leg, prolongedlabour, maternal education status, maternal age more than 25 years, low birth order, length of baby more than $45 \mathrm{~cm}$ and irregular intake of a balanced diet remained independently significant for caesarean delivery. ${ }^{34}$ Maternal complications were found to be more significant in public hospitals than in private ones.Shahabuddin et al revealed that the rates of population-based and facility-based caesarean sections haveincreased linearly among all age groups of womenincluding adolescents. Although the country's overall(population-based) caesarean section rate amongadolescents was within acceptable range (11.6\%), arate of nearly $50 \%$ health facility level caesareansections among adolescent girls is alarming. ${ }^{35}$
Most common causes for elective CS included previous CS (55.7\%) followed by pregnancy with hyper tensive disorder (12.4\%), malpresentation (7.2\%), history of subfertility (6.4\%), diabetes mellitus (5.5\%), patient's desire (5.1\%), bad obstetric history (3.3\%), and multiple pregnancy $(1.9 \%)$ and placenta praevia (1.9\%).Our findings are in partially agreement with the findings of Aminu et al. ${ }^{30}$ They observed that previous CS and "post-term dates" were common indications for elective CS with "post dates"- the commonest indication for CS in primiparous women.

However,it was to be found in this study that patients with history of previous CS were sleeted for elective CS but all patients with postdated pregnancy with oligohydramnios were selected for emergency CS, probable cause may be the presence of associated oligohydramnios.

Though this study show high rate of cesarean section, it failed to show the rising trend between two successive years. Findings of this study are not consistent with the findings of Gjonej et al. They revealed in a prospective study that the average rate of cesarean deliveries of approximately $32.3 \%$ in 2011 to $2013,21.7 \%$ in 1999 to 2000 and the $8.7 \%$ in the year 1982 to 1984 resulting in a rising trend in number of cesarean section. Two success years are not enough time to assess trend of cesarean section. They described the indication previous cesarean births, preeclampsia, and foetal suffering as the indication of cesarean section. The finding seems to be similar to this study. ${ }^{36}$

This study was conducted in a tertiary care military hospital where the samples of the study were taken from the families of soldiers who lived in the Savar Cantonment or nearby. So, the study findings may not represent the whole country.

\section{Conclusion}

Considering the findings of the study, carefull monitoring of the foetus and selecting patients for CS at all levels of health care facilities, and awareness among general population about the complications of the caesarian sections would reduce the caesarian sections. 


\section{References}

1. Joseph PP, Ann MM, Loise JP, Marion S, Rose-mary EP. Medical dictionary: A concise and up-to-date guide to medical terms, Houghton Mifflin Company, USA.

2. WHO. Monitoring obstetric care: a handbook. Geneva: WHO Press, World Health Organization, 2009.

3. World Health Organisation and UNICEF. Countdown 2015: buildinga future for women and children, the 2012 Report. http:// countdown2015mnch.org/ documents/2012Report/2012-Complete.pdf (accessed 9 March 2017).

4. Campbell OM, Graham WJ. Strategies for reducing maternal mortality: getting on with what works. Lancet. 2006; 368:1284-99.

5. Ronsmans C, De Brouwere V, Dubourg Det al. Measuring the need for life-saving obstetric surgery in developing countries. BJOG. 2004;111:1027-30.

6. World Health Organization. Appropriate technology for birth. Lancet 1985; 2:436-37.

7. WHO. Monitoring obstetric care: a handbook. Geneva: WHO Press, World Health Organization, 2009.

8. Betrán AP, Merialdi M, Lauer JA et al. Rates of caesarean section: analysis of global, regional and national estimates. Paediatr Perinat Epidemiol 2007; 21:98-113.

9. Cavallaro FL, Cresswell JA, FrançaGVA,et al. Trends in caesarean delivery by country and wealth quintile: cross-sectional surveys in southern Asia and subSaharan Africa.Bull World Health Organ 2013;91:914-22D.

10. Chu K, Cortier H, Maldonado F, Mashant T, Ford N, Trelles M. Cesarean section rates and indications in sub-Saharan Africa: a multi-country study from Medecins sans Frontieres. PLoS One. 2012;7:e44484.

11. Ye J, Betran AP, Guerrero Vela M, Souza JP, Zhang J. Searching for the optimal rate of medically necessary cesarean delivery. Birth. 2014; 41:237-44.

12. National Institute of Population Research and Training (NIPORT), Mitra and Associates, and ICF International. Bangladesh Demographic and Health Survey 2011. Dhaka, Bangladesh; Calverton, MD, USA: NIPORT, Mitra and Associates, and ICF International, 2013.

13. International Institute for Population Sciences (IIPS), Macro International. National Family Health Survey (NFHS 3), 2005-06.Vol I. Mumbai, India: IIPS, 2007.

14. Ministry of Health and Population (MOHP) [Nepal], New ERA, and ICF International Inc. Nepal Demographic and Health Survey 2011.Kathmandu, Nepal: Ministry of Health and Population, New ERA, and ICF International, Calverton, Maryland, 2012.

15. WHO. Monitoring obstetric care: a handbook. Geneva: WHO Press, World Health Organization, 2009.
16. Althabe F, Sosa C, Belizán J, Gibbons L, Jacquerioz F, Bergel E. Caesareansection rates and maternal and neonatal mortality in low-, medium- andhigh-income countries: an ecological study. Birth. 2006;33:270-77.

17. Souza JP, Gülmezoglu A, Lumbiganon P et al. WHO Global Surveyon Maternal and Perinatal Health Research Group. Caesareansection without medical indications is associated with an increased risk of adverse short-term maternal outcomes: the 2004-2008 WHO. Global Survey on Maternal and Perinatal Health.BMC Med. 2010;8:71.

18. Tollånes MC. Increased rate of caesarean sections causes andconsequences. Tidsskr Nor Laegeforen. 2009;129:1329-31.

19. Mossialos E, Allin S, Karras K, Davaki K. An investigation of caesareansections in three Greek hospitals: the impact of financial incentives and convenience. Eur J Public Health. 2005; 15:288-95.

20. Feng $\mathrm{XL}, \mathrm{Xu} \mathrm{L}$, Guo $\mathrm{Y}$, Ronsmans C. Factors influencing rising caesareansection rates in China between 1988 and 2008. Bull World Health Organ.2012;90:30-9A

21. Lei H, Wen SW, Walker M. Determinants of caesarean delivery amongwomen hospitalized for childbirth in a remote population in China. J ObstetGynaecol Can. 2003; 25:937-43.

22. Habib HA, Abdulla MM, Yacoub SE. Knowledge and preference of mothers delivering at ALKadhumyia Teaching Hospital regarding caesarean sectionand normal vaginal delivery. Iraqi Postgrad Med J. 2011;10:512-18.

23. Koblinksi M, Anwar I, MridhaMK,et al. Reducing maternal mortalityand improving maternal health: Bangladesh and MDG 5.J HealthPopul Nutr2008;26:280-94

24. Neuman M, Alcock G, Azad K et al. Prevalence and determinants of caesarean section inprivate and public health facilities in underserved South Asian communities: cross-sectional analysis of data from Bangladesh, India and Nepal. BMJ Open 2014; 4: e005982.

25. Kyu HH, Shannon HS, Georgiades K et al. Caesarian delivery and neonatal mortality rates in 46 low- and middle-income countries: a propensity score matching and meta-analysis of demographic health survey data. Int J Epidemiol. 2013; 42:781-91.

26. Gibbons L, Belizán JM, Lauer JA, et al. The global numbers and costs of additionally needed and unnecessary caesarean sections performed per year: overuse as a barrier to universal coverage. World Health Report, Background paper. Geneva: World Health Organization. 2010

27. Leone T, Padmadas SS, Matthews Z. Community factors influencing rising caesarean section rates in developing countries: an analysis of six countries. Soc Sci Med. 2008; 67:1236-46.

28. Mazzoni A, Althabe A, Liu NH, et al. Women's preference for caesarean section: a systematic review and meta-analysis of observational studies. BJOG 2011; 118:391-9. 
29. Lowdon, G., \& Derrick, D. C. (2002). Caesarean section or vaginal birth? What difference does it make? AIMS Journal. Spring 2002; 14 (Online) (accessed on 19 April 2018)

30. Aminu M, Utz B, Halim A and van den Broek N. BMC Pregnancy and Childbirth 2014, 14:130. Available at: http://www.biomedcentral.com/14712393/14/130

31. Kaur J, Singh $S$ and Kaur K. Current trend of caesarean sections and vaginal births. Advances in Applied Science Research. 2013, 4:196-202.

32. Shiba M, PardeshiSachin P, Mayadeo Niranjan M, Janki M. Trends in Cesarean Delivery: Rate and Indications. The Journal of Obstetrics and Gynecology of India. 2014; 64:251-54

33. Radha K, Devi GP, R,V.Manjula RV, Chandrasekharan PA. Study On Rising Trends Of
Caesarean Section (C-Section): A Bio-Sociological Effect.OSR Journal of Dental and Medical Sciences 2015;14:10-13.

34. Rahman M, Shariff AA, Shafie A, Saaid R, Tahir RM. Determinants of Caesarean Risk Factor in Northern Region of Bangladesh: A Multivariate Analysis.Iranian J Publ Health, 2014;43:16-27.

35. Shahabuddin ASM, Delvaux, T, Utz, B, Bardají,A, Brouwere VD. Determinants and trends in health facility-based deliveries and caesarean sections among married adolescent girls in Bangladesh. BMJ Open2016;6:e012424.

36. Gjonej R, Poloska A, Keta M, Delija Z, Zyberaj F, Bezhani $\mathrm{V}$ et al. The reasons of rising trend of cesarean section rate year after year. A retrospective study. International Journal of Nursing and Midwifery.2015;7:9-15. 